Selected papers presented at the Eleventh Annual Conference of the Materials Research Society of Serbia, YUCOMAT 2009

\title{
Synthesis, Characterization and Adsorptive Properties of Organobentonites
}

\author{
N. Jović-Jovičićc ${ }^{a *}$, A. Milutinović-Nikolić ${ }^{a}$, P. Banković ${ }^{a}$, B. DojČinović ${ }^{b}$, \\ B. NediĆ ${ }^{c}$, I. GRŽEtiĆ ${ }^{d}$ AND D. JovAnOviĆ ${ }^{a}$ \\ ${ }^{a}$ Institute of Chemistry Technology and Metallurgy, University of Belgrade \\ Department of Catalysis and Chemical Engineering, Njegoševa 12, Belgrade, Republic of Serbia \\ ${ }^{b}$ Institute of Chemistry Technology and Metallurgy, University of Belgrade \\ Department of Chemistry, Njegoševa 12, Belgrade, Republic of Serbia
}

${ }^{c}$ Faculty of Physical Chemistry, University of Belgrade, Studentski trg 12-16, Belgrade, Republic of Serbia

${ }^{d}$ Faculty of Chemistry, University of Belgrade, Studentski trg 12-16, Belgrade, Republic of Serbia

In this paper partial and complete substitution of cations in the interlayer region of clay with different amounts of two aliphatic ammonium cations was performed with aim of synthesis of organobentonites with multipurpose adsorption properties. Domestic clay from Bogovina was submitted according to a common procedure used for the obtention of organobentonite, which comprises the following steps: grinding, sieving, Na-exchange, cation exchange and drying. The samples were characterized by X-ray diffraction and infrared spectroscopy. The incorporation of surfactant molecules into smectite structure lead to constant increase of $d_{001}$ basal spacing. IR absorption bands assigned to methyl and methylene vibrations increased with the increase of surfactant/bentonite ratio and length of aliphatic chain in surfactant molecules. Adsorptive properties of the obtained materials were in accordance with their organophylicity: the adsorption of organic dye increased while the rate of removal of $\mathrm{Pb}^{2+}$ by adsorption decreased.

PACS numbers: 33.20.Ea, 61.05.cp, 68.43.-h, 78.40.-q, 82.65.-r

\section{Introduction}

Bentonites are clays rich in smectite [1] whose properties such as crystal structure and size, cation exchange capacity (CEC), hydration and swelling, thixotropy, bonding capacity, impermeability, plasticity and tendency to react with organic compounds $[2,3]$ make them advantageous for a variety of applications.

Smectites are 2:1 type of aluminosilicate having crystal lattice that consists of two-dimensional layers where central octahedral sheet of alumina is fused to two external silicate layers. Isomorphic substitution within the layers generates negative charges that are counterbalanced by easily replaceable alkali or alkaline earth cations. These cations are defined as exchangeable cations $[4,5]$. Forces holding the stacks together are relatively weak and the intercalation of small molecules between the layers is easy. Smectite can be rendered organophilic by exchanging the exchangeable cations with alkylammonium ions. Quaternary ammonium cations of the general form $\left[\left(\mathrm{CH}_{3}\right)_{3} \mathrm{NR}\right]^{+}$or $\left[\left(\mathrm{CH}_{3}\right)_{2} \mathrm{NRR}^{\prime}\right]^{+}$, where $\mathrm{R}$ and $\mathrm{R}^{\prime}$ are hydrocarbon groups, are usually used in the synthesis of organoclays. Depending on the dimensions of $\mathrm{R}$ and $\mathrm{R}^{\prime}$, organoclays display distinct adsorptive properties and abilities [6].

* corresponding author; e-mail: natasha@nanosys.ihtm.bg.ac.rs
Numerous studies have focused on the investigation of adsorption of nonionic organic compounds to organoclays as a function of surfactant type and loading [7-10]. There are only few studies on adsorption of metals to organoclays [11, 12], and they have revealed that organoclays have ability to adsorb metals. Recently, simultaneous adsorption of various organic and inorganic pollutants has increasingly attracted scientific attention $[13,14]$.

In this paper domestic bentonite clay was modified with different amounts of two quaternary ammonium cationic surfactants: (1-hexadecyl)trimethylammonium bromide (HDTMA-bromide) and (1-dodecyl)trimethylammonium bromide (DDTMA-bromide). X-ray diffraction (XRD) method and infrared (IR) spectroscopy were used to control the degree of intercalation of organic molecules into smectite layers. Test of simultaneous adsorption of toxic metal cation $\left(\mathrm{Pb}^{2+}\right)$ and organic pollutant molecules (Textile dye Acid Yellow 99 - AY99) by the obtained organobentonites was performed.

\section{Experimental}

Starting material was a characterized domestic clay $(<74 \mu \mathrm{m})$ from Bogovina [15, 16]. Quaternary ammonium compounds: (1-hexadecyl)trimethylammonium (HDTMA) bromide $\left[\left(\mathrm{CH}_{3}\right)_{3} \mathrm{NC}_{16} \mathrm{H}_{33} \mathrm{Br}\right]$ and (1-dodecyl)trimethyl-ammonium (DDTMA) bromide $\left[\left(\mathrm{CH}_{3}\right)_{3} \mathrm{NC}_{12} \mathrm{H}_{25} \mathrm{Br}\right]$ were used in the synthesis 
of the organoclays. These surfactants were obtained from Alfa-Aesar Chemical Company, having chemical purity of 98 and 99\%, respectively. Synthetic textile dye - AY99 $\left[\mathrm{C}_{16} \mathrm{H}_{12} \mathrm{CrN}_{4} \mathrm{O}_{9} \mathrm{SNa}\right]$ was obtained from Alfa-Aesar Chemical Company, having chemical purity of $40 \%$. All chemicals were used without further purification. Lead (II) nitrate $\left[\mathrm{Pb}\left(\mathrm{NO}_{3}\right)_{2}\right]$, p.a. was obtained from Aldrich Chemical Company.

Na-bentonite was prepared by stirring $30.0 \mathrm{~g}$ of raw bentonite in $1 \mathrm{dm}^{3}$ of $1 \mathrm{M} \mathrm{NaCl}$ for $24 \mathrm{~h}$. This procedure was repeated three times. The final suspension was filtered through a Buchner funnel. The filtration cake was rinsed with distilled water in order for $\mathrm{NaCl}$ and other exchangeable cations excess to be removed from the sample. Rinsing was repeated until the negative reaction on $\mathrm{Cl}^{-}$ions in filtrate (tested with $0.1 \mathrm{M} \mathrm{AgNO}_{3}$ ) [17].

Cation exchange capacity (CEC) of Na-bentonite was estimated by standard ammonium acetate method [18] and the obtained CEC value was $63.3 \mathrm{mmol} / 100 \mathrm{~g}$ clay.

Organobentonites were prepared by slow addition of $0.10 \mathrm{dm}^{3}$ either HDTMA-bromide or DDTMA-bromide solution into suspension of $3.0 \mathrm{~g}$ of Na-bentonite in $0.10 \mathrm{dm}^{3}$ distilled water. The procedure according to Baskaralingam [19] was adopted [20]. It comprised $24 \mathrm{~h}$ of stirring at room temperature followed by washing with distilled water until negative bromide test with $0.1 \mathrm{M}$ $\mathrm{AgNO}_{3}$ was achieved. The samples were dried at $80^{\circ} \mathrm{C}$. Different surfactant/bentonite ratios $(0.127,0.317,0.633$ and $1.266 \mathrm{~mol} / \mathrm{g}$ ) were applied in the synthesis and these ratios were chosen in accordance with $\mathrm{CEC}$ values. For easier understanding, the degree of exchange $\left(K_{\text {exch }}\right)$ was introduced and used in the further text:

$$
\begin{aligned}
& K_{\text {exch }}=\frac{\text { mmol surf. } / 100 \text { g clay }}{\text { CEC (mmol exchang. cations } / 100 \text { g clay) }} \\
& \quad=\frac{\text { mmol surf. }}{\text { mmol exchang. cations }}
\end{aligned}
$$

where surf. stands for applied surfactant and may be either HDTMA or DDTMA.

The surfactant to bentonite ratio of $0.127,0.317,0.633$ and $1.266 \mathrm{~mol} / \mathrm{g}$ incorporated into formula (1) gives 0.2 , $0.5,1.0$, and 2.0 values of $K_{\text {exch }}$. Depending on $K_{\text {exch }}$ value and type of surfactant used for the synthesis, the samples were denoted as 0.2 HDTMA-B, 0.5 HDTMA-B, 1.0 HDTMA-B 2.0 HDTMA-B, 0.2 DDTMA-B, 0.5 DDTMA-B, 1.0 DDTMA-B and 2.0 DDTMA-B.

$\mathrm{X}$-ray diffraction (XRD) patterns of Na-bentonite and organobentonite powders were obtained using a Philips PW 1710 X-ray powder diffractometer with a $\mathrm{Cu}$ anticathode $(\lambda=0.154178 \mathrm{~nm})$.

ATR-IR spectra of Na-exchanged and organomodified bentonites were obtained using a Thermo Nicolet 6700 FT-IR Spectrofotometer with Smart Orbit Diamond ATR (attenuated total reflectance) accessory.

Different methods were used to estimate $\mathrm{Pb}^{2+}$ ions and AY 99 concentrations before and after the adsorption process. AY 99 concentration was estimated by Thermo
Electron Nicolet Evolution 500 UV-VIS spectrophotometer using $\lambda_{\max }=449 \mathrm{~nm}$, while $\mathrm{Pb}^{2+}$ concentration was estimated by ICP-OES (ICAP 6500 Duo ICP, Thermo SCIENTIFIC Spectrometer) using emission wavelength of analysis $\mathrm{Pb}^{2+} 220.35 \mathrm{~nm}$. It had previously been confirmed that the presence of $\mathrm{Pb}^{2+}$ in AY 99 solutions did not affect either the position or the intensity of the dye corresponding UV-Vis peak.

The adsorption of $\mathrm{Pb}^{2+}$ ions and AY99 from their mixture on the Na-exchanged bentonite and the series of organomodified bentonites was investigated in aqueous solution in a batch system, with respect to contact time. The experiments were performed at room temperature $\left(25^{\circ} \mathrm{C}\right)$ with constant solution volume of $0.050 \mathrm{dm}^{3}$. All experiments were carried out with the same mass of adsorbent of $10.0 \mathrm{mg}$. Starting concentration of mixed solutions was $50 \mathrm{mg} \mathrm{dm}{ }^{-3}$ of both AY 99 and $\mathrm{Pb}^{2+}$ ions. During the experiment the amount of adsorbed pollutants was measured after predetermined periods of time $(15,30,45,60,90,120$ and $180 \mathrm{~min})$.

The adsorption experiments were carried out in a thermostated shaker (Memmert WNE 14 and SV 1422). The samples were withdrawn from the shaker at regular time intervals and solid phase was separated from the solutions by centrifugation. Supernatant solution was used for the measurements.

\section{Results and discussion}

The XRD patterns of the Na-bentonite and the series of HDTMA-bentonites and DDTMA-bentonites are presented in Figs. 1 and 2, respectively.

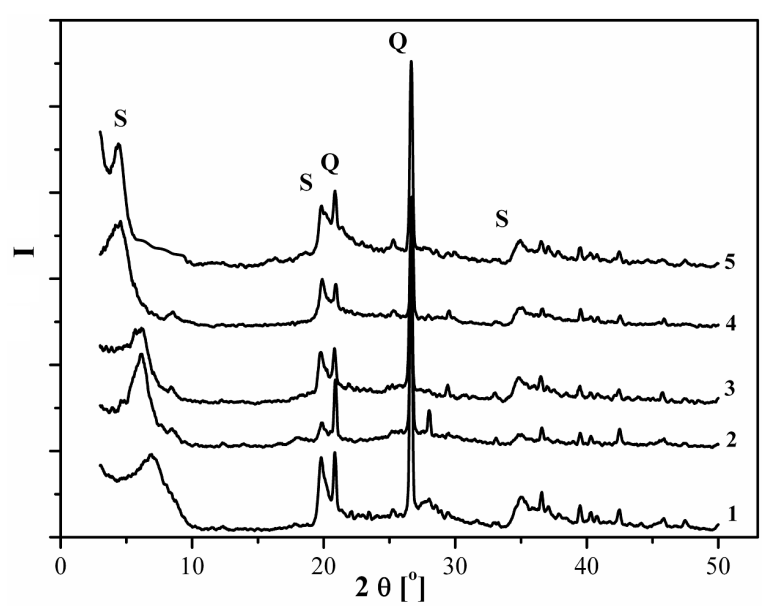

Fig. 1. X-ray diffractograms $(\mathrm{S}=$ smectite, $\mathrm{Q}=$ quartz): (1) Na-bentonite, (2) 0.2 HDTMA-B, (3) 0.5 HDTMA-B, (4) 1.0 HDTMA-B and (5) 2.0 HDTMA-B.

Na-bentonite dominantly consists of smectite in admixture with quartz and minor quantities of other minerals like illite, calcite and feldspar [21, 22]. The incorporation of surfactant molecules into smectite structure lead to constant increase of $d_{001}$ basal spacing. The change 


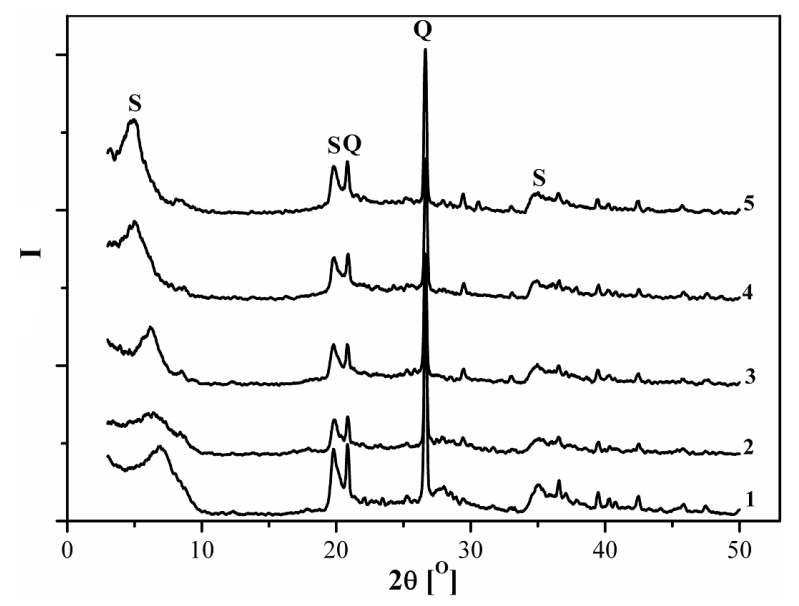

Fig. 2. X-ray diffractograms $(\mathrm{S}=$ smectite, $\mathrm{Q}=$ quartz): (1) Na-bentonite, (2) 0.2 DDTMA-B, (3) 0.5 DDTMA-B, (4) 1.0 DDTMA-B and (5) 2.0 DDTMA-B.

of basal spacing for both investigated organobentonites is presented in Table I.

\section{TABLE I}

The influence of $K_{\text {exch }}$ and type of surfactant on $d_{001}$ basal spacing of smectite.

\begin{tabular}{c|c}
\hline \hline Sample & $\begin{array}{c}d_{001} \text { basal spacing } \\
{[\mathrm{nm}]}\end{array}$ \\
\hline Na-exchanged & 1.28 \\
0.2 HDTMA-B & 1.44 \\
0.5 HDTMA-B & 1.52 \\
1.0 HDTMA-B & 2.00 \\
2.0 HDTMA-B & 2.00 \\
\hline 0.2 DDTMA-B & 1.37 \\
0.5 DDTMA-B & 1.41 \\
1.0 DDTMA-B & 1.78 \\
2.0 DDTMA-B & 1.78
\end{tabular}

Regardless the length of aliphatic chain in surfactant molecule the increase in basal spacing is steady up to $K_{\text {exch }}=1$. Since further increase of $K_{\text {exch }}$ did not result in the increase of the basal spacing it can be assumed that additional surfactant molecules, after replacing all exchangeable interlayer cations, were attached to smectite surface. The length of aliphatic chain in surfactant molecules affected the basal spacing of the obtained organobentonites. For the same $K_{\text {exch }}$ values the corresponding basal spacing of the HDTMA series is greater than in the DDTMA-bentonite series. Therefore, it can be concluded that the increase of length of aliphatic chain in surfactant molecules increases basal spacing of the obtained organobentonites.

The influence of $K_{\text {exch }}$ value on FTIR spectra of the investigated HDTMA series of organobentonite is given in Fig. 3.

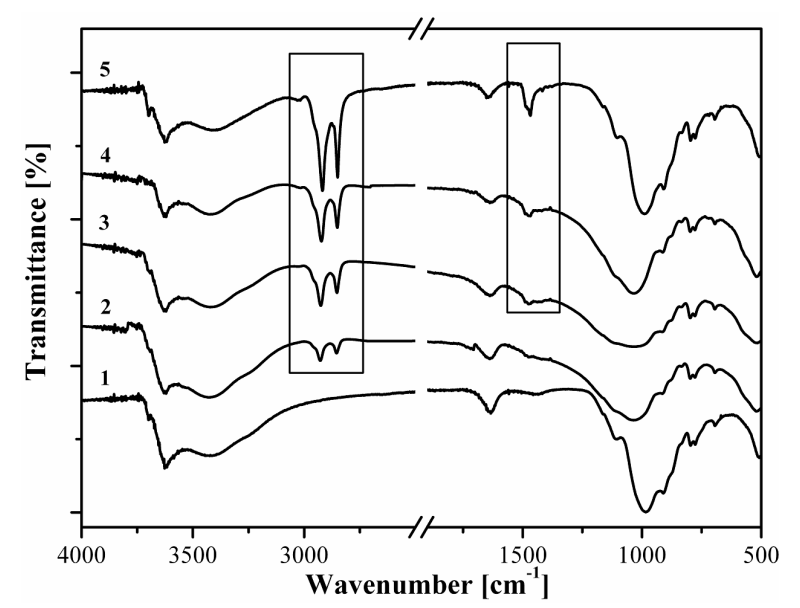

Fig. 3. FTIR spectra registered for: (1) Na-bentonite, (2) 0.2 HDTMA-B, (3) 0.5 HDTMA-B, (4) 1.0 HDTMA-B and (5) 2.0 HDTMA-B.

In FTIR spectra of the Na-bentonite the obtained absorption bands are assigned to vibration in water molecules, smectite, quartz and calcite. Broad bands around 3420 and $1640 \mathrm{~cm}^{-1}$ are attributed to stretching and bending vibrations, respectively, of $\mathrm{OH}$ groups in water molecules. The band around $3620 \mathrm{~cm}^{-1}$ originates from $\mathrm{OH}$ stretching of structural hydroxyl groups in smectite. Smectite originated are also bands at around 1100,1000 and $690 \mathrm{~cm}^{-1}$ assigned to $\mathrm{Si}-\mathrm{O}$ stretching vibrations and $\mathrm{Al}-\mathrm{Al}-\mathrm{OH}$ hydroxyl-bending vibrations at ca. $910 \mathrm{~cm}^{-1}$ [23].

Sharp band at $799 \mathrm{~cm}^{-1}$ with an inflection near $777 \mathrm{~cm}^{-1}$ confirmed that quartz admixture remained unaffected in all investigated samples $[24,25]$. Broad band at $1430 \mathrm{~cm}^{-1}$ assigned to calcite impurity is only distinguished in the Na-bentonite spectrum, while in the organobentonites' spectra this band overlaps with bending vibrations of methyl and methylene groups.

In the organobentonites spectra, beside all bands occurring in the spectrum of Na-bentonite, sharp absorption bands at approximately 2920 and $2850 \mathrm{~cm}^{-1}$ and less expressed one at around $1470 \mathrm{~cm}^{-1}$ were observed. The first two bands can be assigned to the symmetric and asymmetric stretching vibrations of methyl and methylene groups while the third one corresponds to their bending vibrations [26]. As expected the intensity of these bands increased with the increase of $K_{\text {exch }}$ value and organophylicity.

The $K_{\text {exch }}$ value affects the FTIR spectra of the investigated DDTMA series of organobentonite in the same manner as in the HDTMA series. The intensity of methyl and methylene originated vibration bands increased with the increase of $K_{\text {exch }}$ value.

In order to show the influence of length of aliphatic chain in surfactant molecules used for the organobentonite synthesis in Fig. 4 is given a comparison of FTIR spectra of Na-bentonite, 2.0 DDTMA-B and 2.0 HDTMA-B. 


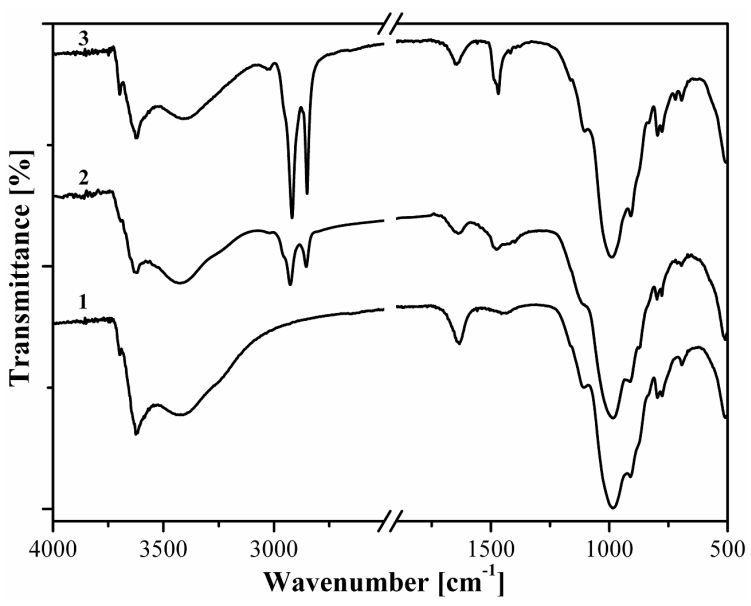

Fig. 4. FTIR spectra registered for: (1) Na-bentonite, (2) 2.0 DDTMA-B and (3) 2.0 HDTMA-B.

As expected the methyl and methylene originated vibration bands at $c a .2920,2850$ and $1470 \mathrm{~cm}^{-1}$ were more intensive for the HDTMA than the DDTMA based organobentonite, since HTDMA molecule contains four methylene groups more.

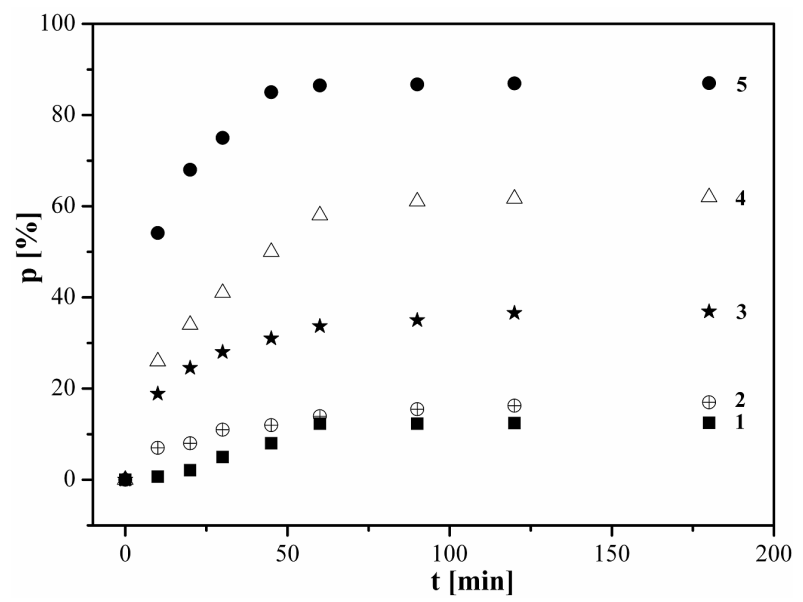

Fig. 5. Adsorption of AY99 from its mixture with $\mathrm{Pb}^{2+}$ ions on: (1) Na-bentonite, (2) 0.2 HDTMA-B, (3) 0.5 HDTMA-B, (4) 1.0 HDTMA-B and (5) 2.0 HDTMA-B.

The effect of contact time on the fraction of AY99 or $\mathrm{Pb}^{2+}$ adsorbed from their mixed solution onto the series of HDTMA-bentonite with different $K_{\text {exch }}$ is presented in Figs. 5 and 6, respectively.

It can be seen from the obtained results that the modification caused change in the adsorbents' adsorption affinity toward the investigated pollutants. The increase in $K_{\text {exch }}$ value from 0.0 (for Na-exchanged) to 2.0 (for 2.0 HDTMA-B) leads to increase of adsorbents' affinity toward AY99 and decrease of their affinity toward $\mathrm{Pb}^{2+}$. These changes are attributed to transition of clay surface from hydrophilic to organophilic. As the organophylicity

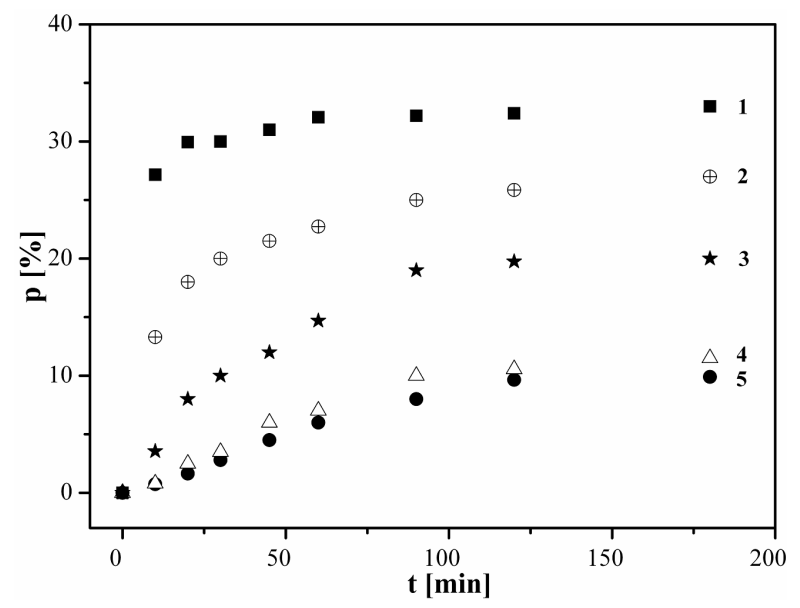

Fig. 6. Adsorption of $\mathrm{Pb}^{2+}$ ions from its mixture with AY99 on: (1) Na-bentonite, (2) 0.2 HDTMA-B, (3) 0.5 HDTMA-B, (4) 1.0 HDTMA-B and (5) 2.0 HDTMA-B.

increased the affinity to organic compound rose, while the opposite occurred for $\mathrm{Pb}^{2+}$ ions. When an adsorbent is more appropriate for chosen adsorbate it possesses at the same time higher adsorption capacity and the adsorption is faster. As an illustration of the adsorption rate, comparison of adsorption half times (time required for $50 \%$ of the total adsorption capacity to be reached, $t_{1 / 2}$ ) for the different investigated adsorbents and adsorbates is given in Table II.

TABLE II

Dependence of the adsorption half time on the type of adsorbent and adsorbate.

\begin{tabular}{c|c|c}
\hline \multirow{2}{*}{$\begin{array}{c}\text { Adsorbate } \\
\text { Adsorbent }\end{array}$} & \multicolumn{2}{|c}{$t_{1 / 2}[\mathrm{~min}]$} \\
\cline { 2 - 3 } & $\mathrm{AY} 99$ & $\mathrm{~Pb}^{2+}$ \\
\hline Na-bentonite & 34 & 6 \\
0.2 HDTMA-B & 20 & 11 \\
0.5 HDTMA-B & 16 & 30 \\
1.0 HDTMA-B & 14 & 43 \\
2.0 HDTMA-B & 8 & 49 \\
2.0 DDTMA-B & 16 & 10
\end{tabular}

From Figs. 5 and 6 and Table II is evident that 2.0 HDTMA-B was more efficient than 1.0 HDTMA-B for AY99 adsorption and less efficient for $\mathrm{Pb}^{2+}$ adsorption. Such behavior can be explained with the fact that in 1.0 HDTMA-B all exchangeable cations are replaced with HDTMA-cation, while the outer clay particle surface retains inorganic character. When the amount of added surfactant exceeds CEC of the clay $\left(K_{\text {exch }}>1\right)$, the excess of surfactant molecules is probably attached to the clay surface, resulting in surface organophilicity and greater affinity to dye molecules and lower affinity to $\mathrm{Pb}^{2+}$. This result supported the obtained XRD results. 


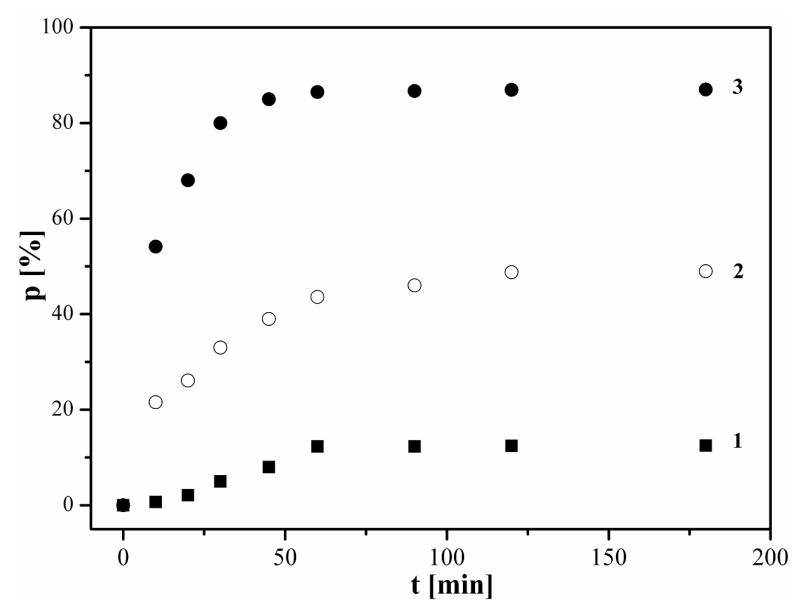

Fig. 7. Adsorption of AY99 from its mixture with $\mathrm{Pb}^{2+}$ ions on: (1) Na-bentonite, (2) 2.0 DDTMA and (3) 2.0 HDTMA-B.

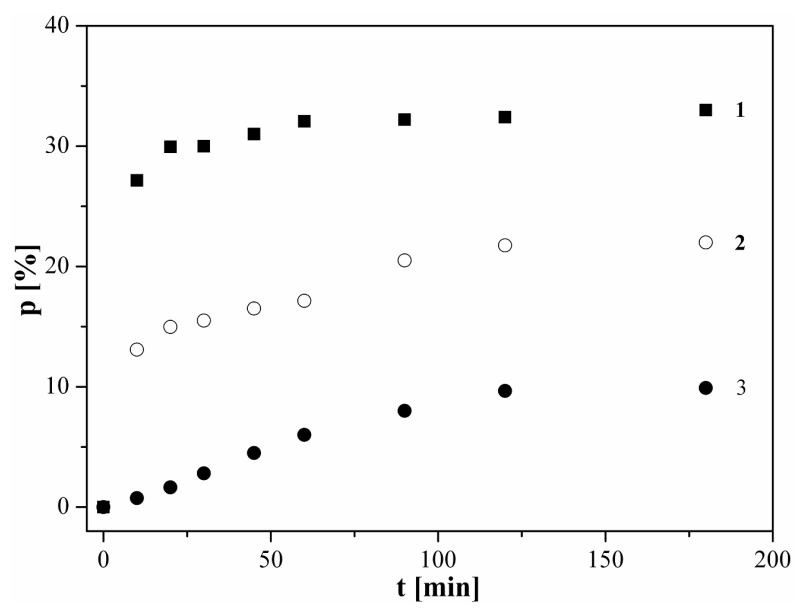

Fig. 8. Adsorption of $\mathrm{Pb}^{2+}$ ions from its mixture with AY99 on: (1) Na-bentonite, (2) 2.0 DDTMA and (3) 2.0 HDTMA-B.

The effect of contact time on the fraction of AY99 or $\mathrm{Pb}^{2+}$ adsorbed from their mixed solution onto Na-bentonite and the most organophylic adsorbent within each of investigated series, namely 2.0 HDTMA-B and 2.0 DDTMA-B, is given in Figs. 7 and 8, respectively.

The increase of length of aliphatic chain in surfactant molecules used for the organobentonite synthesis increases organophylic character of adsorbent and consequently increases adsorption of AY99 and decreases adsorption of $\mathrm{Pb}^{2+}$ ions under the same experimental conditions.

\section{Conclusion}

A series of organobentonites was prepared from domestic smectite based clay with different surfactant/ bentonite ratios in accordance to $\mathrm{CEC}$ values of the Na-exchanged clay. Two alkyl quaternary ammonium cations of structure $\left[\left(\mathrm{CH}_{3}\right)_{3} \mathrm{NR}\right]^{+}$where $\mathrm{R}$ was either hexadecyl and dodecyl were used in the synthesis of HDTMA and DDTMA organoclays, respectively.

For both organoclay series the $d_{001}$ basal spacing increased with increase of surfactant/bentonite ratio until all exchangeable cations between clay layers were replaced with surfactant cations. After replacing all exchangeable interlayer cations, the excess of additional surfactant molecules was most probably attached to smectite surface. The increase of length of aliphatic chain in surfactant molecules increased basal spacing of the obtained organobentonites.

The IR absorption bands assigned to smectite and quartz remain unaffected by the incorporation of surfactants. The rise of bands at approx. $\approx 2920 \mathrm{~cm}^{-1}$, $2850 \mathrm{~cm}^{-1}$ and $1470 \mathrm{~cm}^{-1}$ assigned to methyl and methylene vibrations increased with increase of surfactant/bentonite ratio and length of aliphatic chain in surfactant molecules.

The adsorption of AY 99 increased with increasing HDTMA/bentonite ratio, while the rate of removal of $\mathrm{Pb}^{2+}$ ions by adsorption decreased with increasing organophylicity. The adsorption of AY 99 increase with increase of length of aliphatic chain, while opposite effect was observed for $\mathrm{Pb}^{2+}$. It was confirmed that the synthesized organobentonites might be used as efficient multipurpose adsorbents for simultaneous removal of investigated organic and inorganic pollutants.

\section{Acknowledgments}

This work was supported by the Ministry of Science and Technological Development of the Republic of Serbia (Project 166001B and 142019B).

\section{References}

[1] S.H. Patterson, H.H. Murray, Industrial Minerals and Rocks, New York 1983.

[2] D.E. Highley, Fuller's Earth. Mineral Dossier No. 3, Mineral Resources Consultative Committee, London 1972.

[3] B.K.G. Theng, G. Lagaly, Handbook of Clay Science, Developments in Clay Science Vol. 1 Elsevier, Amsterdam, 2006.

[4] A. Vacari, Catalysis Today 41, 53 (1998).

[5] H.V. Bekkum, E.M. Flanigen, J.C. Jansen, Studies in surface science and catalysis -Introduction to zeolite science and pratice, 58, Chapter 6, Elsevier, New York 1991, p. 201.

[6] Y. Chun, G. Sheng, S. Boyd, Clays Clay Miner. 51, 415 (2003).

[7] T. Pernyeszi, R. Kasteel, B. Witthuhn, P. Klahre, H. Vereecken, E. Klumpp, Appl. Clay Sci. 32, 179 (2006).

[8] L. Zampori, P. Gallo, G. Stampino, Dotelli, Appl. Clay Sci. 42, 605 (2009).

[9] S. Changchaivong, S. Khaodhiar, Appl. Clay Sci. 43, 317 (2009). 
[10] A. Ozcan, C. Omeroglu, Y. Erdogan, A.S. Ozcan, J. Hazard. Mater. 140, 173 (2007).

[11] J.Y. Yoo, J. Choi, T. Lee, J.W. Park, Water Air Soil Pollut. 154, 225 (2004).

[12] V.A. Oyanedel-Craver, J.A. Smith, J. Hazard. Mater. B 137, 1102 (2006).

[13] T. Lee, J. Choi, J.W. Park, Chemosphere 49, 1309 (2002).

[14] V.A Oyanedel-Craver, M. Fullera, J.A. Smith, J. Colloid Interface Sci. 309, 485 (2006).

[15] Z. Vuković, A. Milutinović-Nikolić, J. Krstić, A. Abu-Rabi, T. Novaković, D. Jovanović, Mater Sci. Forum 494, 339 (2005).

[16] Z. Vuković, A. Milutinović-Nikolić, Lj. Rožić, A. Rosić, Z. Nedić, D. Jovanović, Clays Clay Miner. 54, 697 (2006).

[17] H. He, Q. Zhou, W.N. Martens, T.J. Kloprogge, P. Yuan, Y. Xi, J. Zhu, R.L. Frost, Clays Clay Miner. 54, 689 (2006).

[18] Environmental Protection Agency, 1986. Method 9080 - Cation exchange capacity of soils (ammonium acetate). www.epa.gov/epawaste/hazard/ testmethods/sw846/.../methindx.pdf .
[19] M. Baskaralingam, D. Pulikesi, V. Elango, S. Ramamurthi, J. Sivanesan, J. Hazard. Mater. 128, 138 (2006)

[20] N. Jović-Jovičić, A. Milutinović-Nikolić, I. Gržetić D. Jovanović, Chem. Eng. Technol. 31, 567 (2008).

[21] D.M.C MacEwan, M.J. Wilson, Crystal Structures of Clay Minerals and their X-ray Identification, Mineralogical Society, London, 1980.

[22] International Center for Diffraction Data - Joint Committee on Powder Diffraction Standards, Powder diffraction data, Swarthmore, PA, USA, 1990.

[23] J. Madejová, P. Komadel, Clays Clay Miner. 49, 410 (2001).

[24] P. Falaras, I. Kovanis, F. Lezou, G. Seiragakis, Clay Minerals 34, 221 (1999).

[25] J. Madejová, P. Komadel, B. Čičel, Clay Miner. 29, 319 (1994)

[26] A.S. Özcan, B. Erdem, A. Özcan, J. Colloid Interf. Sci. 280, 44 (2004). 